\title{
Erratum to: Voriconazole-induced periostitis
}

\author{
Christine Rossier • Vincent Dunet • Frederic Tissot • \\ Berengère Aubry-Rozier • Oscar Marchetti • \\ Ariane Boubaker
}

Published online: 26 October 2011

(C) Springer-Verlag 2011

\section{Erratum to: Eur J Nucl Med Mol Imaging}

\section{DOI 10.1007/s00259-011-1922-x}

The original manuscript was submitted for publication with an incorrect first name attributed to the co-author Oscar Marchetti.

The online version of the original article can be found at http://dx.doi. org/10.1007/s00259-011-1922-x.

C. Rossier $\cdot$ V. Dunet $\cdot$ A. Boubaker Department of Nuclear Medicine, CHUV and University of Lausanne, Lausanne, Switzerland

F. Tissot $\cdot$ O. Marchetti

Department of Medicine, Infectious Diseases Service, CHUV and University of Lausanne,

Lausanne, Switzerland

B. Aubry-Rozier

Center of Bones Diseases, CHUV and University of Lausanne,

Lausanne, Switzerland

C. Rossier $(\bowtie)$

Department of Nuclear Medicine, CHUV,

Rue du Bugnon 46,

CH-1011 Lausanne, Switzerland

e-mail: Christine.Rossier@chuv.ch

C. Rossier

e-mail: christine.rossier@igr.fr 